\title{
APLIKASI PENDATAAN PELAMAR DAN PENEMPATAN KERJA PADA PT AMONG MITRABAKTI UTAMA
}

\author{
Indah Suciati ${ }^{1}$, Yulianingsih ${ }^{2}$, Soepardi Harris ${ }^{3}$ \\ Program Studi Teknik Informatika, Fakultas Teknik dan Ilmu Komputer, \\ Universitas Indraprasta PGRI \\ Jalan Raya Tengah No 80, Kelurahan Gedong, Pasar Rebo, Jakarta Timur \\ indah.suciati95@gmail.com¹, yuliaunindra@gmail.com ${ }^{2}$, soepardiharris@yahoo.co.id ${ }^{3}$
}

\begin{abstract}
Abstrak
PT. Among Mitrabakti Utama merupakan perusahaan yang bergerak pada bidang outsourcing. Perusahaan yang beralamatkan di Jl. Tanah Merdeka Raya No. 18 A ini setiap harinya selalu ada kegiatan perekrutan karyawan, namun yang sangat disayangkan adalah pegelolaan data pelamarnya masih menggunakan sistem manual. Hal ini menimbulkan banyak kendala, diantaranya waktu yang dibutuhkan untuk pendataan pelamar sampai penempatan kerjanya membutuhkan waktu yang panjang, banyaknya data ganda, seringkali adanya loss data, serta membutuhkan waktu yang lama untuk pembuatan laporan bulanan kepada Manager, dikarenakan harus merekap terlebih dahulu dan harus melihat satu persatu berkas yang sudah ada. Tujuan dibuatnya aplikasi ini untuk dapat meminimalisir semua kendala yang telah dialami selama ini. Dalam pembuatan aplikasi pendataan pelamar dan penempatan kerja ini, metode perancangan yang digunakan adalah Unified Modeling Language (UML) dengan aplikasi Netbeans IDE 8.2 dan MySQL untuk perancangan basis datanya, kemudian metode pengembangan sistemnya menggunakan Waterfall.
\end{abstract}

Kata Kunci: Pendataan, Pelamar, Penempatan Kerja, Java, MySQL, UML

\begin{abstract}
PT. Among Mitrabakti Utama is a company engaged in outsourcing. The company is addressed at Jl. Tanah Merdeka Raya No. 18 A everyday there are always employee recruitment activities, but what is unfortunate is that the management of applicant data still uses a manual system. This causes many obstacles, including the time needed for the collection of applicants until the work placement takes a long time, the amount of double data, often the loss of data, and takes a long time to make a monthly report to the Manager, because they must first and must see one by one the existing files. The purpose of this application is to minimize all obstacles that have been experienced so far. In the creation of this applicant data collection and work placement application, the design method used is Unified Modeling Language (UML) with Netbeans IDE 8.2 and MYSQL applications for database design, then the system development method using Waterfall
\end{abstract}

Keywords: data collection of applicants, work placement, Java, UML.

\section{PENDAHULUAN}

Perkembangan teknologi informasi semakin meningkat seiring dengan kemajuan, perkembangan teknologi berbasis komputasi sangat banyak digunakan untuk mencakup segala aspek diberbagai bidang. Perusahaan membutuhkan suatu sistem yang dapat meningkatkan kinerja agar menjadi lebih efisien. Sistem suatu aplikasi memiliki peranan sebagai media pengolah data.. Aplikasi adalah suatu subkelas perangkat lunak komputer yang memanfaatkan kemampuan komputer langsung untuk melakukan suatu tugas yang diinginkan pengguna (Nazrudin, 2012). Pendataan adalah kegiatan mengumpulkan informasi yang diperoleh dari pengamatan dimana data bisa berupa angka-angka atau lambing (Riyadi, 2012). Pelamar kerja adalah orang yang mengajukan lamaran untuk jabatan tertentu dalam perusahaan. Penempatan kerja adalah kebijaksanaan terhadap sumber daya manusia untuk menentukan posisi atau jabatan seseorang (Badriyah, 2019).

PT. Among Mitrabakti Utama merupakan perusahaan yang bergerak pada bidang outsourcing. Sistem yang digunakan saat ini masih berbasis manual, dengan menggunakan perangkat lunak bantu, Microsoft excel. Hal ini mengakibatkan terhambatnya proses perekrutan, dimulai dari pendataan pelamar sampai pembuatan laporannya. Atas dasar permasalahan tersebut, perancangan aplikasi pendataan pelamar dan penempatan kerja berbasis java netbeans ini menjadi solusi yang 
tepat agar seluruh proses pendataan sampai laporan menjadi lebih terkomputerisasi dan efektif.

\section{PENELITIAN RELEVAN}

Penelitian relevan yang digunakan peneliti untuk acuan menyusun pembuatan sistem ini, salah satunya dari penelitian karya (Alusia Ivana Valmai, dkk., 2014) dengan judul "Sistem Informasi Kepegawaian di Kantor Pusat Andi Offset" hasil penelitian tersebut bertujuan dapat meningkatkan efisiensi dan efektivitas operasional departemen personalia dalam mengelola dan mencatat Sumber Daya Manusia.. Penelitian selanjutnya dari karya (Saepurrahman dkk, 2019) dengan judul "Sistem Pencatatan Dan Pendataan Manajemen Sumber Daya Manusia Dengan Model Scrum Pada PT. Bintang Trans Khatulistiwa" Hasil Penelitian tersebut bertujuan untuk membantu bagian HRD untuk menjalankan tugasnya, mulai dari proses pendataan karyawan, pendataan absensi, pengajuan cuti, proses payroll atau penggajian dan penilaian karyawan hingga pembuatan laporan, serta dapat menghasilkan informasi yang dapat digunakan untuk pengambilan keputusan bagi seorang manajer.

\section{METODE PENELITIAN}

Penelitian ini, peneliti menggunakan Metode Waterfall. Model waterfall disebut juga sebagai model siklus hidup klasik. Model ini memungkinkan pemecahan misi pengembangan yang rumit menjadi beberapa langkah logis (desain, kode, pengujian, dan seterusnya) dengan beberapa langkah yang pada akhirnya menjadi produk akhir yang siap pakai (Purwanto dkk, 2019). Metode pengumpulkan data peneliti lakukan untuk mendapatkan data dan informasi yang mendukung hasil dari penelitian ini antara lain:

\section{Observasi}

Peneliti mengamati dan mempelajari pengelolaan pendataan pelamar dan penempatan kerja baik manual maupun menggunakan data Microsoft Office Excel yang terdapat di PT. Among Mitrabakti Utama, mulai dari penginputan data pelamar dari file ke Microsoft Office Excel, pencetakan surat pengantar penempatan sampai pembuatan laporan hasil recruitment kepada Manager.

2. Wawancara

Wawancara merupakan proses memperoleh keterangan untuk tujuan penelitian dengan cara melakukan tanya jawab kepada responden ataupun pihak-pihak yang terkait, dengan mengajukan beberapa pertanyaan yang ada kaitannya dengan kebutuhan data yang dikumpulkan oleh peneliti. Peneliti mewawancari Saudari Andina Elfira Noza, selaku Kepala HRD yang bertanggung jawab dalam penerimaan karyawan baru. Pada masa PSBB, wawancara tetap dilakukan secara tatap wajah, dikarenakan lokasi penelitian merupakan tempat bekerja peneliti.

3. Studi Kepustakaan

Pada metode ini peneliti mempelajari materi yang berhubungan dengan karya tulis yang diajukan melalui beberapa buku pada perpustakaan online, catatan kuliah dan sarana perpustakaan.

\section{HASIL DAN PEMBAHASAN \\ Use Case Diagram}

Use Case Diagram sistem yang diusulkan pada aplikasi pendataan pelamar dan penempatan kerja pada PT. Among Mitrabakti Utama sebagai berikut: 


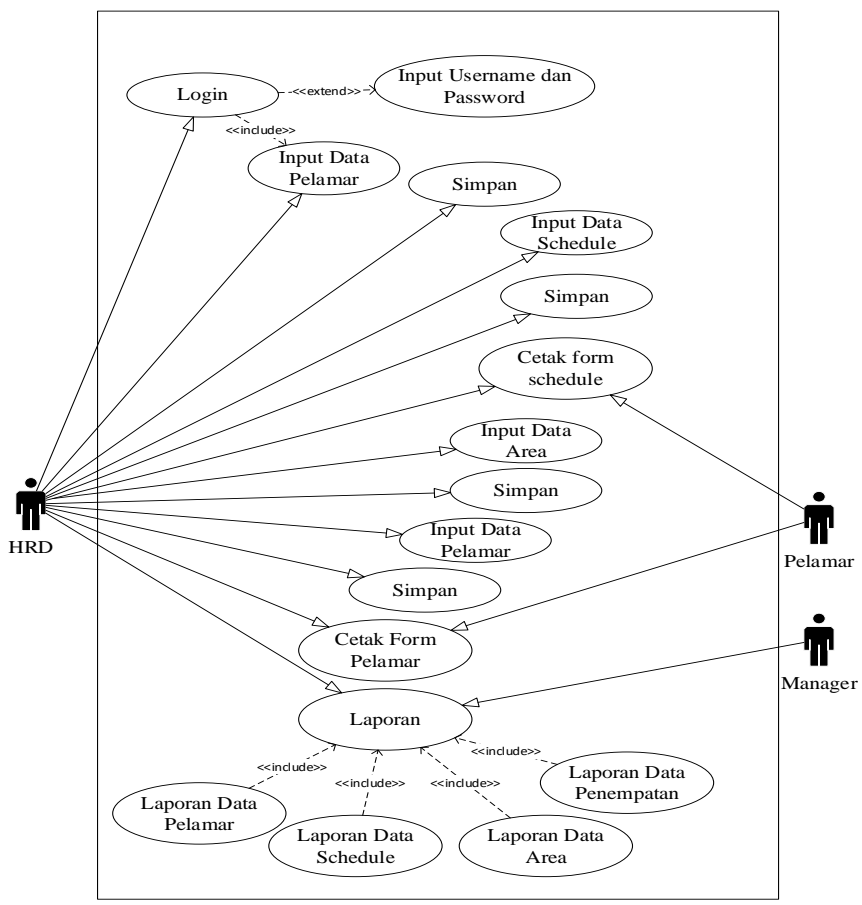

Gambar 1. Use Case Diagram

\section{Class Diagram}

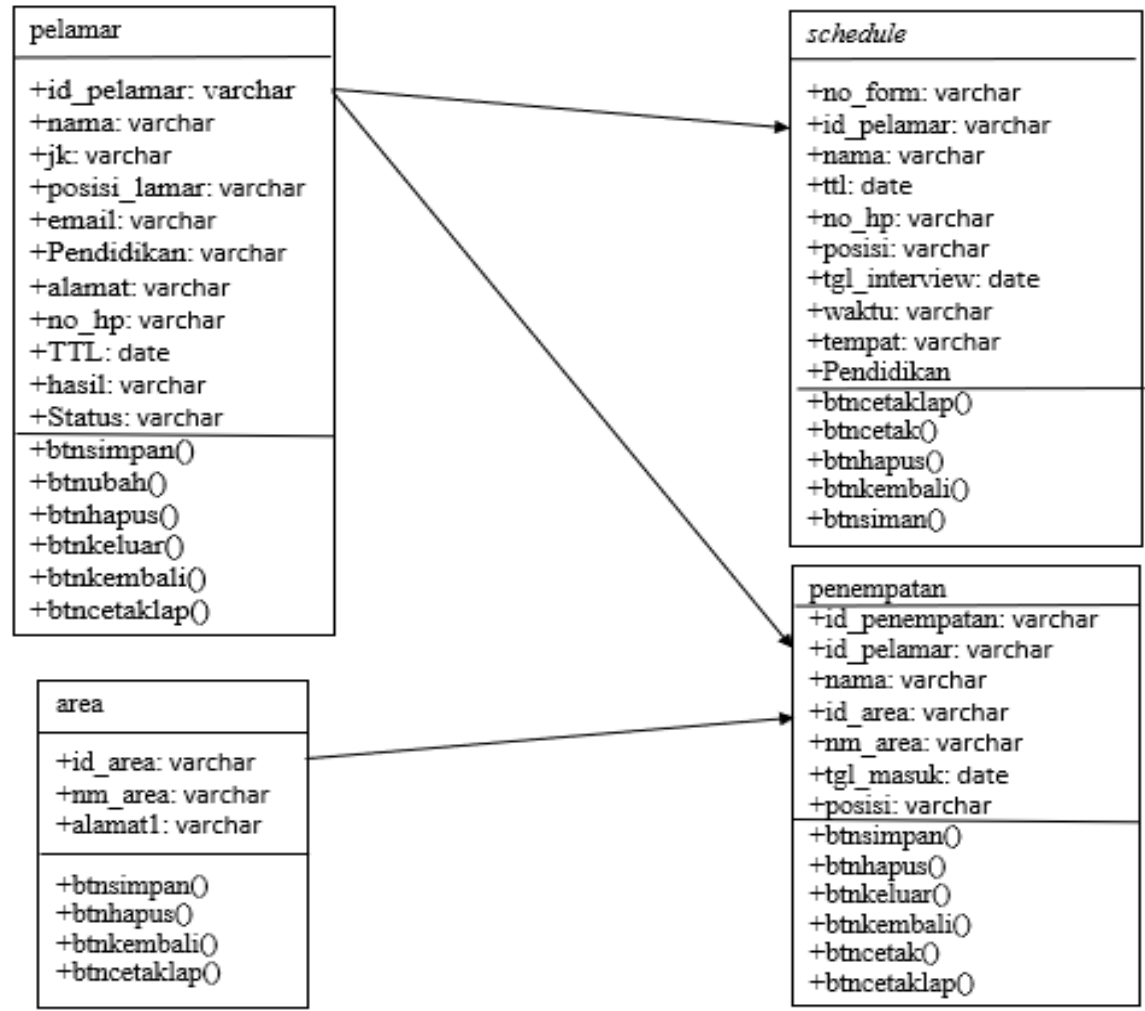

Gambar 2. Class Diagram 


\section{Tampilan Layar}

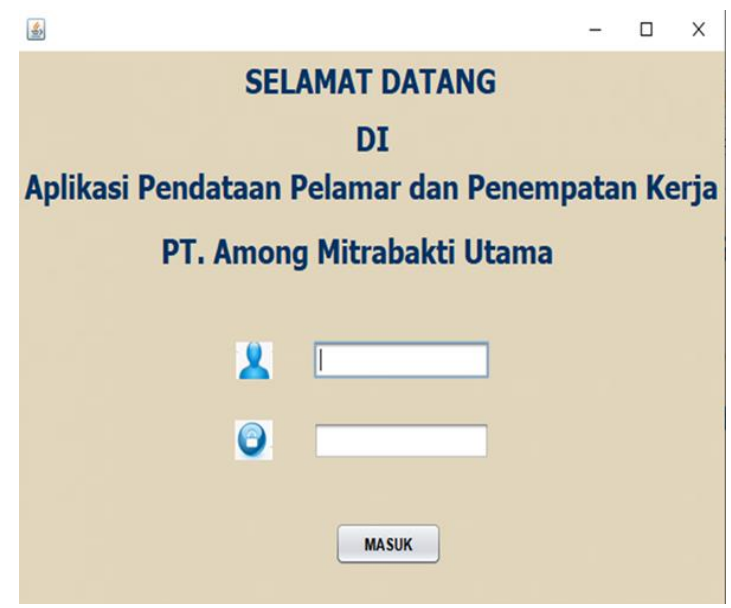

Gambar 3. Tampilan Layar Login

Tampilan Layar Login ini ada diawal saat pengoperasian progam aplikasi pendataan pelamar dan penempatan kerja. HRD memasukkan id pengguna dan kata sandi, setelah itu pilih tombol masuk maka akan menampilkan halaman menu.

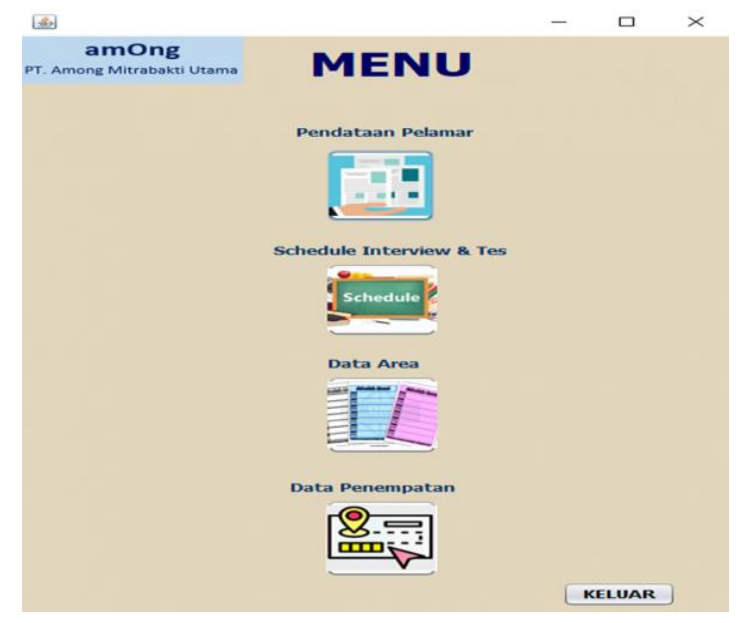

Gambar 4. Tampilan Layar Menu

Tampilan Layar Menu ini tampil setelah selesai memasukkan id pengguna dan kata sandi. Pada halaman ini akan menampilkan pilihan halaman yang ingin dioperasikan, seperti pendataan pelamar, schedule interview \& tes, data area, dan data penempatan.

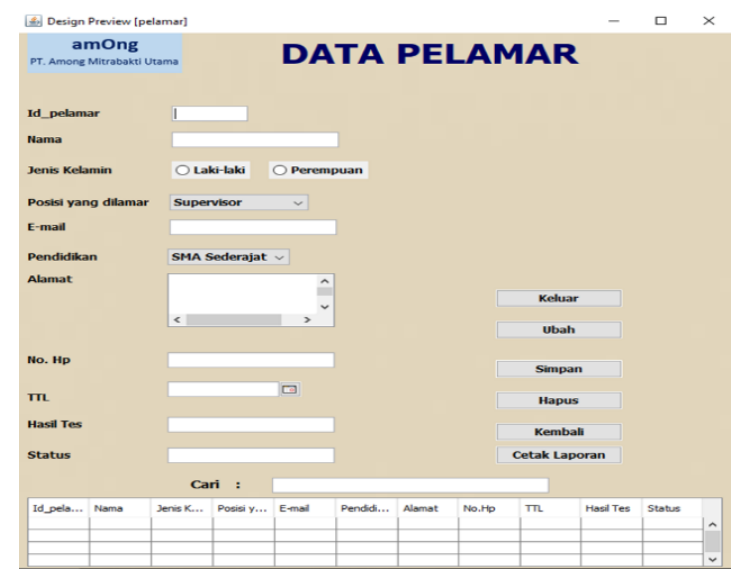

Gambar 5. Tampilan Layar Data Pelamar 
Tampilan Layar Data Pelamar ini untuk diisi HRD untuk melengkapi data diri pelamar, dan akan menyimpan ke database.

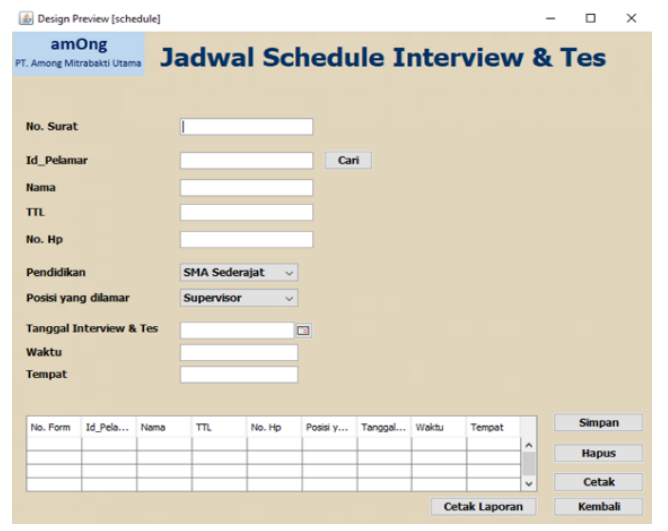

Gambar 6. Tampilan Layar Data Schedule Interview \& Tes

Tampilan Layar Data Schedule Interview \& Tes ini untuk diisi HRD untuk menjadwalkan interview dan tes pelamar yang akan di cetak untuk pelamar.

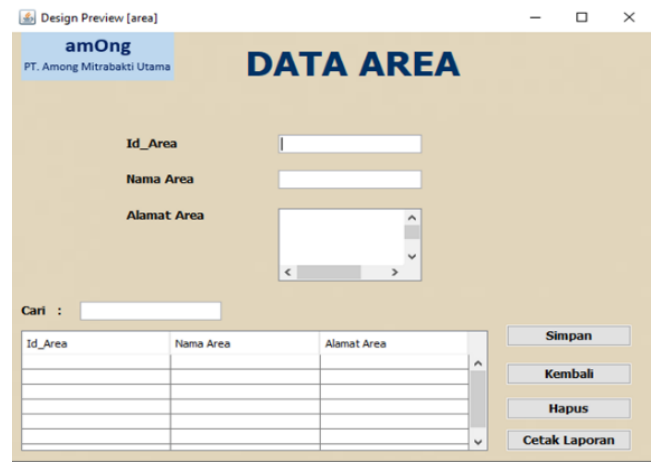

Gambar 7. Tampilan Layar Data Area

Tampilan Layar Data Area ini diinput setiap ada area baru, dan berfungsi juga pada form penempatan kerja untuk menampilkan area mana karyawan ditempatlkan.

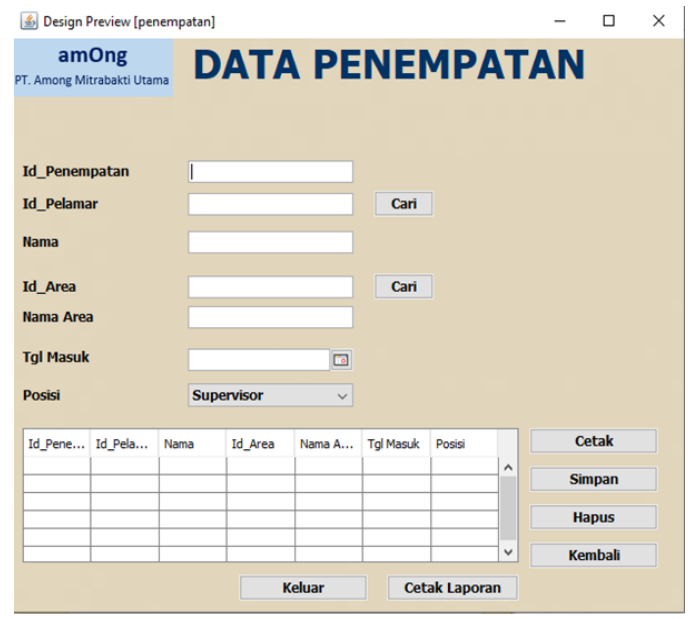

Gambar 8. Tampilan Layar Data Penempatan

Tampilan layer data penempatan diinput Ketika pelamar sudah dinyatakan diterima dan akan di tempatkan di area tersebut. 


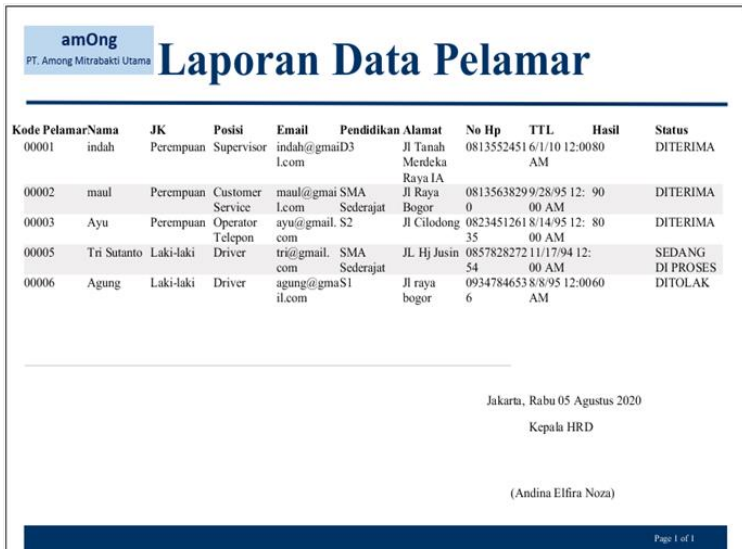

Gambar 9. Tampilan Layar Laporan Data Pelamar

Pada tampilan form laporan data pelamar ini berisi data-data yang ada pada tabel data pelamar. Laporan ini tampil ketika HRD mengklik tombol cetak laporan pada halaman data pelamar.

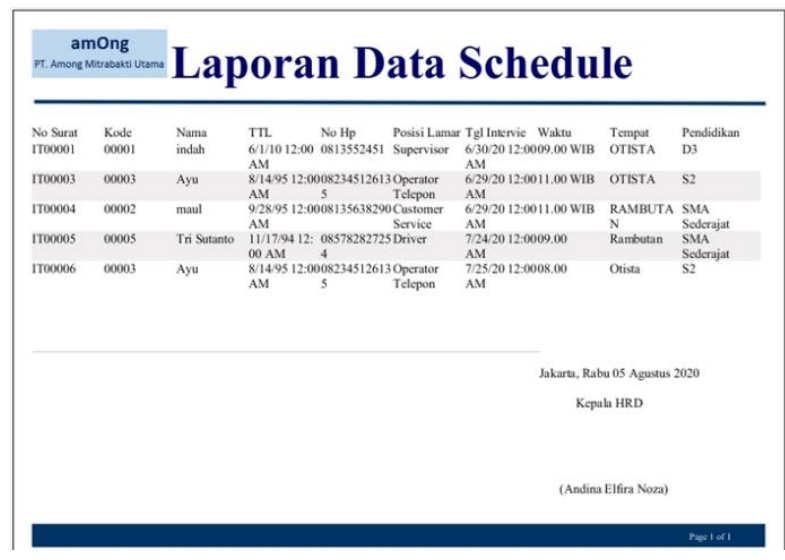

Gambar 10. Tampilan Layar Data Schedule

Pada tampilan form laporan data schedule ini berisi data-data yang ada pada tabel schedule interview \& tes. Laporan ini tampil ketika HRD mengklik tombol cetak laporan pada halaman data schedule interview \& tes.

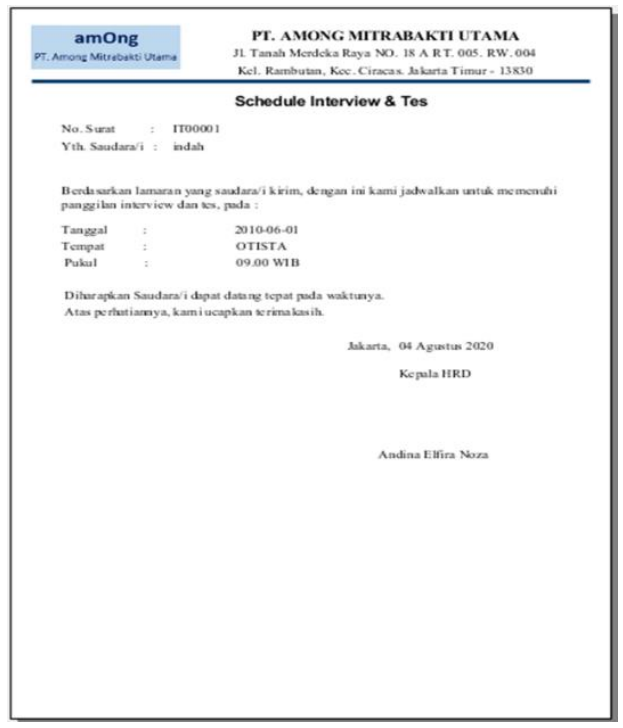

Gambar 11. Tampilan Layar Surat Schedule 
Pada tampilan form surat schedule ini surat untuk pelamar sebagai bukti ada panggilan interview \& tes. Laporan ini tampil ketika HRD mengklik tombol cetak pada halaman data schedule interview \& tes.

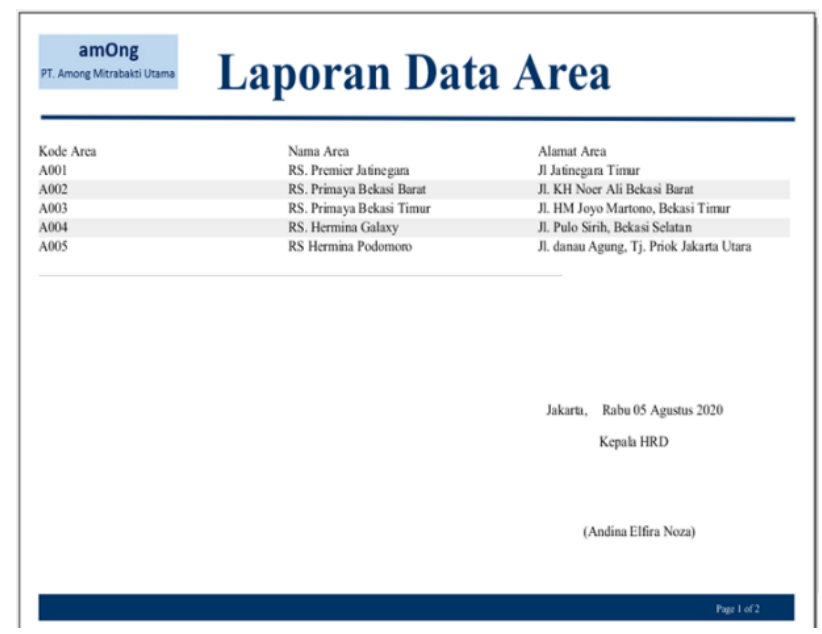

Gambar 12. Tampilan Layar Data Area

Pada tampilan form laporan data area ini berisi data-data yang ada pada tabel area. Laporan ini tampil ketika HRD mengklik tombol cetak laporan pada halaman data area.

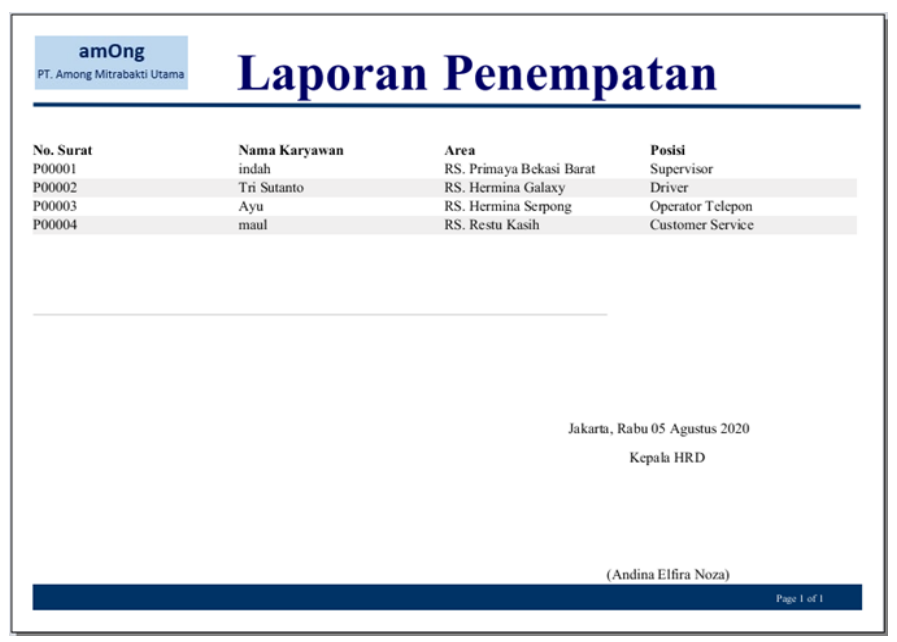

Gambar 13. Tampilan Layar Data Penempatan

Pada tampilan form laporan penempatan ini berisi data-data karyawan yang sudah ditempatkan ke area. Laporan ini tampil ketika HRD mengklik tombol cetak laporan pada halaman data penempatan

\section{SIMPULAN}

Dengan dibuatnya aplikasi pendataan pelamar dan penempatan kerja pada PT. Among Mitrabakti Utama dapat memudahkan HRD dalam mengolah data dengan cepat dan akurat serta dapat memudahkan pencarian data dan di update dengan mudah. Aplikasi yang telah dibuat dengan bahasa pemrograman Java NetBeans dan penyimpanan data pada database MySQL dapat memberikan kelancaran dalam menginput dan penyimpanan data-data sehingga tidak terjadi kesulitan dalam pencarian data-data tersebut dalam proses penginputan maupun dalam pembuatan laporan. 


\section{DAFTAR PUSTAKA}

Edy, S. (2009). Manajemen Sumber Daya Manusia. Jakarta: Kencana.

Gata, G., Prabowo, Y., \& Kusuma, R. A. (2017). Sistem Informasi Pengelolaan Sumber Daya Manusia E-Recruitment Dalam Bidang Jasa Penyalur Kerja. Jurnal Ilmiah FIFO, 9(2), 138. https://doi.org/10.22441/fifo.2017.v9i2.007

Harfizar, H., Yuliana, K., \& Muh Afiffudin, M. A. (2017). Perancangan Sistem Informasi Pendataan Karyawan Pada Perusahaan Jasa Berbasis Web. SENSI Journal, 3(2), 190-207. https://doi.org/10.33050/sensi.v3i2.777

Hikmat Nugraha, I., \& Melasari. (2019). Sistem Informasi Pengolahan Data Karyawan Berbasis Web di Percetakan Quick Corp Tanuwijaya Tasikmalaya. Jurnal Teknik Informatika.

Iqbal, M., Sihombing, R. A., \& Halimatusha'diah, H. (2020). Perancangan Outsource Management System Berbasis Web pada PT Sigma Cipta Utama. Jurnal Riset Dan Aplikasi Mahasiswa Informatika (JRAMI). https://doi.org/10.30998/jrami.v1i02.170

Rahman, S., Setiawan, A., \& Handriani, I. (2019). Sistem Pencatatan Dan Pendataan Manajemen Sumber Daya Manusia Dengan Model Scrum (Studi Kasus: Pt Bintang Trans Khatulistiwa). JSAI (Journal Scientific and Applied Informatics). https://doi.org/10.36085/jsai.v2i1.138

Setiawan, F. I., Adiningsih, A. R., Widayat, W., \& Wijayanto, F. (2012). Pengembangan sistem informasi manajemen rekrutmen asisten laboratorium. Seminar Nasional Aplikasi Teknologi Informasi 2012 (SNATI).

Syahriani, \& Satria, J. (2017). Rancangan Aplikasi E-Recruitment Karyawan Dengan Metode Waterfall. Jurnal Swabumi. Valmai, A. I., \& Santoso, H. B. (2014). Sistem Informasi Kepegawaian. Eksis.

Yusmawi, W., Putra, I., \& Syari, D. (2016). Rancang Bangun Program Aplikasi Penempatan Tenaga Kerja OutsourcinG. Jurnal Ipteks Terapan. https://doi.org/10.22216/jit.2015.v9i2.36 